\title{
¿Se puede medir la diversidad en el campo de la edición de libros en relación a la independencia editorial?
}

\section{Peut-on mesurer la diversité dans le domaine de l'édition de livres en relation avec l'indépendance éditoriale?}

\author{
Christian Robin \\ Universidad Paris 13 / Labsic \\ Integrante del Labsic \\ ChristianRobin@wanadoo.fr
}

\begin{abstract}
Resumen
El vínculo entre diversidad e independencia de los editores es abordado a menudo. Se examina aquí la posibilidad de medir la diversidad de los enfoques cualitativos y cuantitativos e introducir la noción de independencia como parámetro. Esto plantea la cuestión de los diferentes significados de la palabra diversidad según las épocas socio-culturales. Sin olvidar el impacto que puede tener lo digital sobre la independencia editorial digital, su producción y usos. Se constata la gran dificultad de un estudio que requiere de diferentes enfoques que incorporen miradas de largo plazo en el análisis de las producciones, los usos y los procesos. Las evoluciones que introduce lo digital en la producción y los usos corren el riesgo, por lo demás, de una rápida obsolescencia de los hallazgos de las investigaciones.
\end{abstract}

Palabras Clave: Diversidad, independencia, libros, edición, digital.

\section{Résumé}

Le lien entre diversité et indépendance des maisons d'édition est souvent avancé. Nous étudions ici la possibilité de mesurer la diversité avec des approches qualitatives ou quantitatives et en introduisant le paramètre de l'indépendance. Se pose la question des différents sens du mot diversité selon les ères socioculturelles. Sans oublier l'influence que peut avoir le numérique sur l'indépendance éditoriale, les productions et leurs usages. On constate la grande difficulté d'une étude qui nécessite des approches diverses intégrant à la fois des analyses sur les productions, les usages, les processus et toujours à long terme. Les évolutions 
qu'induit le numérique dans les productions et les usages risquent, par ailleurs, de rendre très vite les constats caducs.

Mots Clés: Diversité, indépendance, livres, édition, numérique

\section{INTRODUCCIÓN}

Los profesionales de la edición y quienes hacen la observación de este campo relacionan la cuestión de la independencia editorial con la de la diversidad. Por lo tanto, parece interesante analizar este vínculo y, para ello, examinar la posibilidad de medir ambas variables y establecer posibles correlaciones entre ellas.

La cuestión de la diversidad en las industrias culturales es un elemento mayor en las políticas públicas de la cultura y ha sido objeto de numerosos estudios, pero, paradójicamente, este no ha sido el caso durante mucho tiempo para la primera de las industrias culturales: la edición de libros. Esta parecía, quizás, un poco menos estratégica que la prensa o la televisión para los investigadores.

Sin embargo, en el curso de los últimos años en Francia, los trabajos de los economistas como Valdenaire (2003), Benhamou (2006), Moreau y Peltier (2011) han permitido dar una primera luz sobre estos temas. Además, como parte de una investigación financiada por el Ministerio de Cultura de Francia, una serie de trabajos se publicaron en 2011 bajo el titulo de Diversidad e industrias culturales. El vínculo con la independencia editorial atraviesa estas dos publicaciones, aunque a veces ronda a través de las nociones de concentración o financiarización.

Si bien han sido publicados recientemente, todos estos trabajos reposan sobre datos antiguos ( hasta el año 2007). Pero la distribución digital influye probablemente de manera diferente hoy en día debido a su uso desde nuevas categorías de libros, fenómeno que se suma al cada vez más fuerte impacto de las ventas de libros en la Web. Este último elemento, en consecuencia, constituye la tercera variable mencionada en este artículo.

Los estudios señalados son los únicos, aunque la pregunta sobre la diversidad en el campo de la edición de libros ocupa muchos otros trabajos a nivel internacional. Sin embargo, como vamos a ver, las materias estudiadas varían significativamente.

No vamos a volver aquí a la difícil definición de independencia. Para una crítica de las publicaciones anteriores, ordenada en tres puntos - los enfoques cuantitativos y cualitativos, otro significado para la palabra diversidad y la relación entre la diversidad y lo digital- trataremos de proponer pistas tomando en cuenta la evolución reciente del sector de la edición libros. 


\section{¿ENFOQUES CUALITATIVOS O CUANTITATIVOS?}

Las obras citadas permiten establecer la imposibilidad de un enfoque unidimensional de la diversidad. Por lo tanto, la medición de la diversidad pasa por enfoques diversos. Exploremos estos análisis.

Benhamou, Moreau y Peltier se basan en una medida de la diversidad definida por Stirling (1999) en términos de variedad, equilibrio y disparidad. Aplicada a los libros, la variedad analiza el número de diferentes títulos producidos y vendidos. Con el equilibrio, se observa, bajo distintos ángulos, las cuotas de mercado y los volúmenes de ventas de los títulos. La disparidad permite completar la información sobre los títulos por medios de los más vendidos. Todas estas consideraciones son retomadas para el análisis de las disparidad respecto de los autores.

Estos análisis exclusivamente cuantitativos se basan en los datos de GFK, un panel que recoge los datos de 2.300 puntos de venta en el año 2007. Los análisis se centraron en tres ámbitos: la literatura, la literatura para jóvenes y los cómics.

Peltier (2006) llevó a cabo una investigación sobre el mismo tema junto a Benhamou para el período 1990-2003 sobre la base de estadísticas del Sindicato Nacional de la Edición (SNE). El cambio en la metodología, que estaba relacionada con la necesidad de datos más completos sobre las ventas por título y no sobre los datos de la producción, permitió nuevas conclusiones. El estudio del período 19902003 concluyó con la existencia de una oposición entre diversidad de la oferta y la diversidad de la demanda. Esto llevó a los autores a formular una hipótesis cuestionando la existencia de una preferencia por la diversidad, lo que correspondería a "la incapacidad de los consumidores para tomar sus decisiones frente a una oferta pletórica" (2006, p. 340). El estudio más reciente mostró unas oposiciones menos sencillas. Los autores concluyen que "el peso de las editoriales líderes en los cómics y libros para jóvenes se reducen de forma continua en favor de los pequeños editores". Los autores también hacen hincapié en que las ventas en línea son "favorables tanto para los autores desconocidos, como también para las superestrellas" (2011, p. 11).

Es cierto que los períodos considerados tienen duraciones muy diferentes y corresponden a períodos en los que las ventas en línea no podrían tener el mismo efecto. Por no hablar, incluso en el estudio del período 2003-2007, de la distribución de obras en forma digital.

Una de las primeras críticas sobre el último estudio en esta materia está relacionado con la necesidad de un análisis respecto a un largo período. Por ejemplo, las constataciones sobre la concentración de las ventas en algunos títulos están muy influenciadas por el tipo de best-seller que domina un determinado año. El lanzamiento de un Dan Brown en literatura en 2004 o en 2012 o de un Zep en el cómic puede alterar por completo la apreciación sobre el período. La extensión de este estudio sobre los años siguientes permitiría refinar sus conclusiones. 
Una segunda crítica se refiere a la representatividad de los datos proporcionados por GFK. Los resultados generales de GFK, que ahora se elevan a 2.800 puntos de venta, parecen ser muy representativos del mercado. Sin embargo, este no es el caso para algunos títulos. Por lo tanto, si realizamos un estudio utilizando la misma base de 2009, la comparación de los datos obtenidos con los de los editores para las obras de fondos (cerca de 20 años en ventas y cerca de 200 títulos) mostró que los números de los libros cuyas ventas fueron inferiores a 500 copias no eran del todo fiables.

Los resultados con respecto a las obras de menores ventas merecen ser relativizados. Además, la sobrerrepresentación de los hipermercados (GSA) en comparación con los pequeños puntos de venta susceptibles de vender la producción local, puedellevar a una subestimación de la actividad de las pequeñas estructuras editoriales locales (y a menudo independientes). Así vemos que las pequeñas editoriales independientes pueden ser el punto ciego del estudio, a pesar de que los volúmenes totales reportados están cerca de la realidad del mercado. Este no sería el caso en el Reino Unido, donde Bookscan proporciona una imagen más completa del mercado de los libros.

La tercera crítica se refiere a los límites de una evaluación cuantitativa de los libros producidos o adquiridos (la noción de lectura no es tomada en cuenta), aunque el criterio de disparidad intenta abordar el aspecto cualitativo.

Otros estudios se detienen en una combinación de enfoques cualitativos y cuantitativos. A esa perspectiva se puede unir todo el trabajo en torno a las traducciones, ya sea por el equipo reunido en torno a Sapiro, que el libro Las contradicciones globalización editorial (2009) presentó al público; así como otros enfoques tales como el del Informe sobre la Diversidad (2011) de Wischenbart o el del Análisis de los fondos de bibliotecas presentado por Dickey (2010). Estos estudios proporcionan una mejor apreciación de la circulación de libros en el mundo y un mejor análisis de la evolución del dominio del idioma inglés y de la dialéctica que se crea con las lenguas "minoritarias" y territorios. Los resultados son de nuevo muy matizados. Wischenbart señala que los autores publicados por pequeñas estructuras editoriales pueden encontrar un público internacional, al menos a nivel europeo. Las multinacionales no tienen el monopolio de la internacionalización.

Sin embargo, estos estudios nos proporcionan información principalmente sobre la diversidad de libros publicados, pero solo a veces sobre los vendidos. Asimismo, se centran a menudo en la literatura y las humanidades, haciendo caso omiso de la mayoría de los libros que se publican en otros sectores editoriales. Se subestima de esta manera el impacto de coediciones o coproducciones.

Hemos discutido este aspecto en un trabajo que no tenía la intención de medir la diversidad. Aplicamos un método que permite analizar las tendencias en los contenidos de los libros ilustrados o de referencia, describiéndolos según varias decenas de criterios.

Los resultados fueron inequívocos en lo concerniente al desarrollo de una producción diversificada durante un período de 20 años y sobre una fuerte 
disminución de la concentración entre los principales editores. La crítica principal de este trabajo tiene relación con haber analizado solo la producción y no el consumo. Para avanzar en la cuantificación de la calidad de este tipo de obras se debería cruzar este enfoque con las compras de acuerdo a las estadísticas de Moreau y Peltier. Quedan las dificultades en la evaluación de las ventas reales de los títulos de baja rotación.

Otro enfoque trata de analizar el domonio de los actores en el mercado. Un ejemplo de ello es el texto de Ménard, Concentración y diversidad en la industria del libro (2006), que se ocupa del caso de Quebecor en la provincia de Quebec (Canadá). El autor llega a la siguiente conclusión :

Hay que insistir en la complejidad de las mediaciones inter-empresas e interpersonales que enlazan a quienes toman las decisiones financieras (Quebecor) con actores en el terreno mismo (editores, difusores, líderes de otras filiales del grupo). Así, el dominio de los imperativos económicos desde arriba de la cadena del libro y de las otras filiales mediáticas del grupo no parecen pesar directamente sobre las decisiones editoriales, sino sobre la elección de los títulos (y autores) que benefician de una difusión amplia sobre la totalidad del grupo mediático, en nombre de una mejor adecuación a las competencias del grupo (2006, p 11).

Este tipo de análisis no se pretende globalizante y se entiende que la realización de muchos estudios de este tipo podría ayudar a comprender mejor el tema de la diversidad editorial.

El análisis desarrollado en La diversidad en el sector del libro, entre cuyos autores varios participan de este seminario, se sitúa bajo esta concepción, tratando de responder la mayoría de las críticas ya expuestas. El sector de la edición de libros es abordado bajo un enfoque más complejo. Los autores hacen hincapié en la necesidad de estudiar primero las estructuras editoriales y su relación con la concentración y la "financiarización" (consideremos que este término parece estar fuera de moda cuando precisamente estamos en el centro de una crisis financiera...) así como su nivel de organización. Este punto hace eco precisamente de las conclusiones de Menard. El análisis cuantitativo de la producción o de las ventas se complementa con el del proceso editorial y su impacto sobre la diversidad. La lectura ya no es un punto ciego de la investigación sobre la diversidad, especialmente al interrogarse sobre la oferta y el uso de las bibliotecas. También se aborda la cuestión del impacto de las políticas públicas y las perspectivas de la digitalización. Además, Tristan Mattelart nos lleva a una deconstrucción del concepto de diversidad en otro de los artículos del libro.

La principal crítica que se puede hacer a este texto y por extensión a esta comunicación, es de quedarse en el nivel del catálogo de las investigaciones por realizar. Esto, probablemente, refleja la dificultad de tratar el tema de forma más cualitativa. 


\section{OTRO SIGNIFICADO DE LA DIVERSIDAD}

Consignemos que un breve párrafo de esta contribución permite introducir un factor pasado por alto en las investigaciones francófonas, pero que se encuentra en el centro del concepto de diversidad en su versión inglesa (diversity): las personas involucradas en la producción de libros, desde el autor al vendedor pasando por el editor. Encontramos allí un sentido de la palabra diversidad que se ha convertido en la valija para describir diversos orígenes culturales en el sentido de los orígenes étnicos no europeos. Esta cuasi ausencia de cuestionamiento -en Francia- sobre el tema de la diversidad editorial se basa en la dificultad de nombrar el tema (y muchas veces la negativa a considerarlo). En los Estados Unidos y Gran Bretaña, la endogamia europea (caucásica, en versión inglesa) del mundo editorial parece ser un factor limitante de la diversidad, puesto que existirían ciertas categorías de personas que no podrían acceder a la publicación por este motivo.

Estudios británicos (2007) mostraron la baja representación de BME (black and minority ethnic groups) entre el personal de la edición británica. Lo mismo se constata en la representación en los libros (sobre todo las tapas) de estas minorías.

Pero, ¿la medición de este sentido de la diversidad editorial puede hacerse en Francia? La respuesta es bastante negativa, dados los problemas legales que ello plantea. Sin embargo, sabemos que este tipo de mediciones aún se pueden realizar. No obstante, no encontramos huellas de ello en la obra de Legendre y Abensour sobre los primeros novelistas (2012) o en aquellas de Lahire sobre los escritores (2006). Queda entonces una fuerte presunción respecto al acceso limitado de estas categorías de población a la publicación o al empleo en la edición francesa. ¿Es esto cierto en las estructuras independientes? Esta pregunta queda abierta. Se podrían hacer las mismas observaciones para las cuestiones de género, que síse han estudiado en los libros escolares en Francia.

\section{DIVERSIDAD Y DIFUSIÓN DIGITAL}

En todas las publicaciones mencionadas en esta presentación, los cambios vinculados al desarrollo de la distribución digital de obras se han discutido en términos de futuro o han sido ignorados. Esta pregunta debe ahora formularse en tiempo presente.

Sabemos que la tecnología digital ha cambiado tanto el proceso de publicación como las publicaciones mismas. Algunas, como las enciclopedias en varios volúmenes, han desaparecido, reduciendo así la bibliodiversidad, pero la función que cumplen ha sido trasladada a la Web. Otras se han transformado, como algunos libros prácticos o profesionales, ya sea apoyándose sobre el componente objeto o sobre el servicio en el que el libro es solo un aspecto. En general, el uso de las tecnologías 
digitales ha dado lugar a un número creciente de publicaciones que promueven la diversidad producida. Y ello, sobre todo, porque la tecnología digital ha permitido el desarrollo de herramientas de apoyo a la escritura y a la publicación. Esta ayuda a la escritura puede llegar a permitir que gente no competente en este ámbito - debido a su baja escolarización o discapacidad-pueda comunicarse por escrito sin pasar por un intermediario humano.

¿Lo digital ayuda a medir la diversidad editorial? Sin lugar a dudas. De hecho, la mayor parte de las investigaciones no habrían sido posibles sin las computadoras.

¿Lo digital complica la tarea? Efectivamente, y ello por varias razones. En primer lugar, por la multiplicación de las publicaciones que trastorna cada día un poco más la frontera entre la auto-publicación y la publicación profesional. Los números de la nueva auto-publicación en los Estados Unidos lo demostrarían, a condición de que estos datos tengan algún valor. ¡En este campo, la independencia editorial es reina!

Abensour y Legendre han establecido criterios para definir el límite mínimo de la pequeña editorial. Estos son los parámetros de profesionalismo que: "respetan los derechos de autor, política editorial y valor añadido" (2007, p. 18). En 2012, estos bordes dieron probablemente paso a muchos nuevos "editores" digitales.

El trastorno también surge de la definición misma del concepto de libro. En efecto, en su versión digital, ¿nos limitaremos a los libros homotéticos? ¿Dónde está la línea que separa un libro denso de una sencilla aplicación?

\section{CONCLUSIÓN}

Visto así, es difícil medir la diversidad editorial, incorporando el concepto de independencia en el contexto del desarrollo dela difusión digital de las obras. Debemos primero ponernos de acuerdo sobre lo que se mide, puesto que los significados de la diversidad son múltiples y, en ocasiones, contradictorios. ¿Se trata acaso de libros variados publicados por editoriales variadas o bien de historias, personas, situaciones representadas, cuestiones abordadas, formas de lidiar con estas cuestiones, lo que resulta diverso? Podemos tener una gran variedad de libros de una amplia variedad de editoriales independientes muy auto centradas (lo que es caricaturizado en el campo literario francés como "germanopratisme").

La segunda dificultad proviene de la noción de independencia editorial, que ya hemos criticado en otros lugares. ¿Tal vez deberíamos utilizar la definición de las pequeñas editoriales profesionales propuestas por Abensour y Legendre? ¿Sabiendo aún que lo digital es una herramienta de medición que puede eliminar la relevancia de esta definición ? Debemos, además, tener en cuenta que la influencia de lo digital puede, paradojicamente, hacer obsoletas a largo plazo las tendencias que acá tratamos y que fueron necesarias para realizar este estudio. 


\section{Referencias bibliográficas}

Benhamou, F. y Peltier, S. (2006). Une méthode multicritère d'évaluation de la diversité culturelle : application à l'édition de livres en France. En Greffe, X. (Dir.), Création et diversité au miroir des industries culturelles. Paris: La documentation française.

Bouquillion, P. y Combès, Y. (2011). Diversité et industries culturelles. Paris : L'Harmattan.

Diversity in Publishing network. (2007). Ethnic Diversity in Publishing report. London: Diversity in Publishing network.

Kovač, M. y Wischenbart, R. (2011). Diversity Report 2010. Viena: Rüdiger Wischenbart Content \& Consulting.

Legendre, B. y Abensour, C. (2007). Regards sur l'édition T1 et 2. Paris: La documentation française.

Ménard, M. (2006). Concentration de la propiété et diversité de la production dans l'industrie du livre au Québec: le cas de Quebecor. Extraído desde http:// www.observatoire-omic.org/colloque-icic/pdf/MenardTR1.pdf.

Moreau, F. y Peltier, S. (2011). La diversité culturelle dans l'industrie du livre en France (2003-2007). Culture études, 2011-4.

Sapiro, G. (Dir.). (2009). Les contradictions de la globalisation éditoriale. Paris: Nouveau monde éditions.

Stirling, A. (1999). On the Economics and Analysis of Diversity. Electronic paper, 28. Valdenaire, K. (2003). Concentration économique et diversité culturelle : le cas du livre en France, thèse de 3e cycle sous la direction de Joëlle Farchy. Paris: Université Panthéon-Sorbonne. 